\title{
Multi-GCM ensembles performance for climate projection on a GIS platform
}

\author{
Salem S. Gharbia ${ }^{1} \cdot$ Laurence Gill $^{1} \cdot$ Paul Johnston $^{1} \cdot$ Francesco Pilla $^{1}$
}

Received: 26 May 2016/Accepted: 4 June 2016/Published online: 15 June 2016

(C) Springer International Publishing Switzerland 2016

\begin{abstract}
Climate impact studies especially in the field of hydrology often depend on climate change projections at fine spatial resolution. General circulation models (GCMs), which are the tools for estimating future climate scenarios, run on a very coarse scale, so the output from GCMs need to be downscaled to obtain a finer spatial resolution. This paper aims to present GIS platform as a downscaling environment through a suggested algorithm, which applies statistical downscaling models to multidimensional GCMEnsembles simulations. Climate change projections for the Shannon River catchment in Ireland were developed for several climate variables from multi-GCM ensembles for three future time intervals forcing by different Representative Concentration Pathways (RCP): all these processes are implemented in a GIS platform through designed and developed GIS-based algorithm. This algorithm is used as a downscaling tool in GIS environment, which is unprecedented in literature. Statistical downscaling methods were used in the projection process after a particular verification and performance evaluation using several techniques such as Taylor diagram for each GCM-ensembles within independent sub-periods. The established statistical relationships were used to predict the response of the future
\end{abstract}

Salem S. Gharbia

GharbiaS@TCD.ie

Laurence Gill

laurence.gill@tcd.ie

Paul Johnston

PJHNSTON@tcd.ie

Francesco Pilla

fpilla@tcd.ie

1 Department of Civil, Structural and Environmental Engineering, Trinity College, Dublin, Ireland climate from simulated climate model changes of the coarse scale variables. Significant changes in temperature, precipitation, wind speed, solar radiation and relative humidity were projected at a very fine spatial scale. It was concluded that the main source of uncertainty was related to the GCMs simulation and selection. In addition, it was obvious to conclude that GIS platform is an efficient tool for spatial downscaling using raster data forms.

Keywords Climate change - RCP · GCM - Ensembles · Shannon · GIS · Downscaling

\section{Introduction}

During the last half century, the global climate has experienced warming because of the continuous increase of greenhouse gases concentrations in the atmosphere, which have been attributed to human activities (Stocker et al. 2013b). Continued increases in greenhouse gas emissions at or above current rates will cause further warming during the 21 st century which has been predicted to be greater than that observed during the 20th century (Stocker et al. 2013b; Solomon 2007). Projections of future climate change under scenarios obtained using climate system models have important practical significance, particularly for climate impact assessment studies and future emission control strategies (Stocker et al. 2013b; Xiaoge et al. 2013).

General circulation models (GCMs) are an essential tool in order to understand and help to predict the impacts of climate change. These numerical coupled models combine several earth systems including the atmosphere, oceans, land surface and sea-ice and offer considerable potential for the study of climate change and variability (Fowler et al. 2007). These climate models have been evolving 
steadily over the past several decades and in addition, are the most adapted tools for studying the impact of climate change at a regional scale. Recently, fully coupled Atmosphere-Ocean GCMs, along with transient methods of forcing the concentration of greenhouse gases, have brought considerable improvement in the results obtained from climate model (Tripathi et al. 2006).

Modelling the impacts of climate change onto different environment systems requires high-resolution regional data for future scenarios of temperature and precipitation and other climatic factors (Salathe et al. 2007). The current resolution of the GCMs, on average, is more than two polar degrees on the earth's surface for both directions in each pixel, which is close to a few hundred kilometres between grid points. Hence, GCMs typically provide output at grid boxes, which are tens of thousands of square kilometres in area, whereas the scale of interest with respect to most environmental system impact studies is of the order of a few hundred square kilometres, or even less.

Several downscaling methodologies have thus been developed to deal with this problem of mismatch of spatial scales (Tripathi et al. 2006), such as dynamical downscaling [regional climate models (RCMs)] and statistical downscaling methods. RCMs are developed based
Fig. 1 Map of the Shannon catchment with the Shannon River, climate stations and the catchment surface elevation highlighted

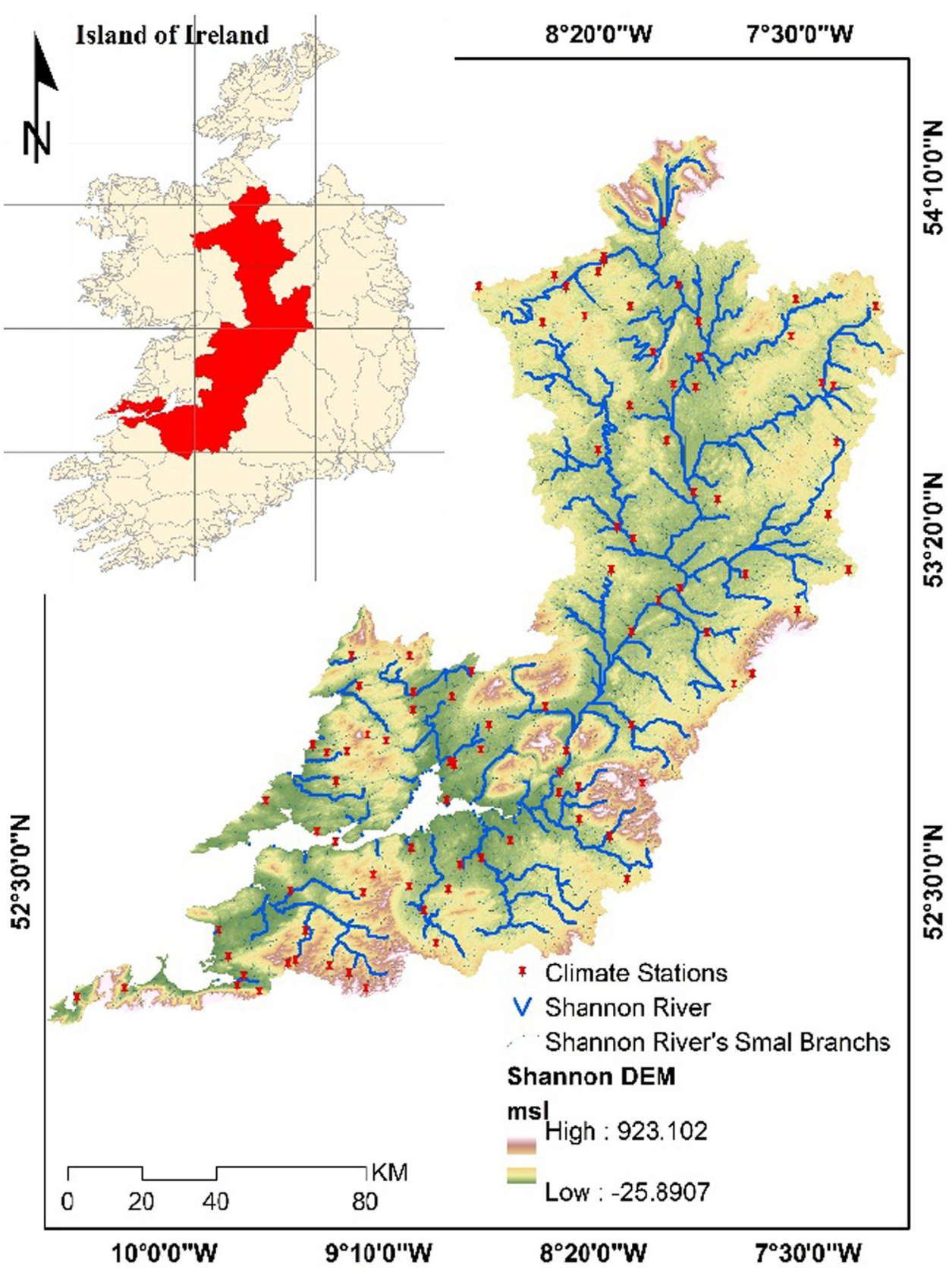




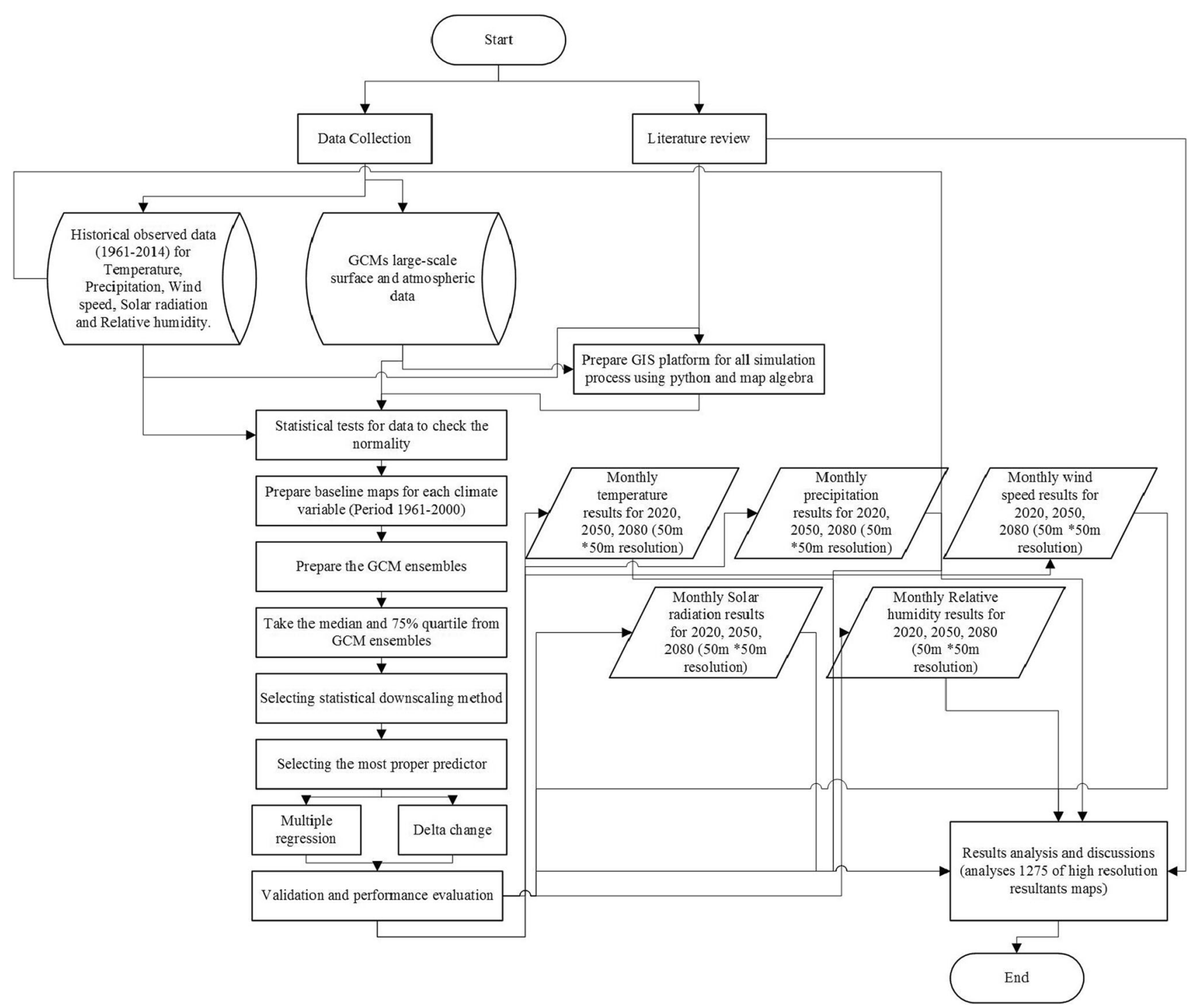

Fig. 2 General framework flowchart

Table 1 Multi-GCM ensembles models details

\begin{tabular}{lll}
\hline GCM & Institution & Resolution \\
\hline CSIRO-MK3.0 & CSIRO, Australia & $175 \mathrm{~km} \times 175 \mathrm{~km}$ \\
MIROC-H & Centre for Climate Research, Japan & $100 \mathrm{~km} \times 100 \mathrm{~km}$ \\
HADGEM1 & Hadley Centre, UK & $125 \mathrm{~km} \times 125 \mathrm{~km}$ \\
NCAR-CCSM & National Centre for Atmospheric Research, USA & $125 \mathrm{~km} \times 125 \mathrm{~km}$ \\
CanESM2 & Canadian Climate Centre, Canada & $128 \mathrm{~km} \times 128 \mathrm{~km}$ \\
\hline
\end{tabular}

Table 2 climate models validation statistical tests results

\begin{tabular}{|c|c|c|c|c|c|c|}
\hline Predictands & Method & Predictors & $\mathrm{R}$ & $\mathrm{R}^{2}$ & Ad- $R^{2}$ & SE \\
\hline Temperature & Delta-change & Temperature & 0.97 & 0.95 & 0.94 & 0.02 \\
\hline Precipitation & Delta-change & Precipitation & 0.97 & 0.94 & 0.93 & 1.58 \\
\hline Wind speed & Multiple regression model & Temperature and precipitation & 0.96 & 0.93 & 0.92 & 0.71 \\
\hline Solar radiation & Multiple regression model & Temperature and precipitation & 0.95 & 0.91 & 0.89 & 5952.5 \\
\hline Relative Humidity & Multiple regression model & Temperature and precipitation & 0.87 & 0.78 & 0.73 & 1.75 \\
\hline
\end{tabular}


on dynamic formulations using initial and time-dependent lateral boundary conditions of GCMs to achieve a higher spatial resolution at the expense of limited area modelling. The main problem of RCMs is the computational cost and so it is only available for limited regions. Moreover, despite improvements, outputs of RCMs are still too coarse for some practical applications, such as hydrological catchment impact studies, which need local and site-specific climate scenarios. Hence, statistical downscaling techniques have been developed to overcome these challenges (Chen et al. 2011; Quintana Segui et al. 2010; Seguí et al. 2010; Willems and Vrac 2011). In such environmental system impact studies, the emission scenario and the GCM are the main sources of uncertainty (Maurer and Hidalgo 2008; Boé et al. 2007).
Unfortunately, each step of the downscaling procedure also has associated uncertainties which all add up and constitute a cascade of uncertainty that must be taken into account (Seguí et al. 2010; Quintana Segui et al. 2010).

Recently, a set of scenarios known as representative concentration pathways (RCPs) have been adopted by climate researchers to provide a range of possible futures for the evolution of atmospheric composition. These RCPs have started to replace earlier scenario-based projections of atmospheric composition. For example, the RCPs are being used to drive climate model simulations as part of the World Climate Research Programme's Fifth Coupled Model Intercomparison Project (CMIP5) and other comparison exercises (Meinshausen et al. 2011; Moss et al. 2008, 2010; Taylor et al. 2009b, 2012). Since climate

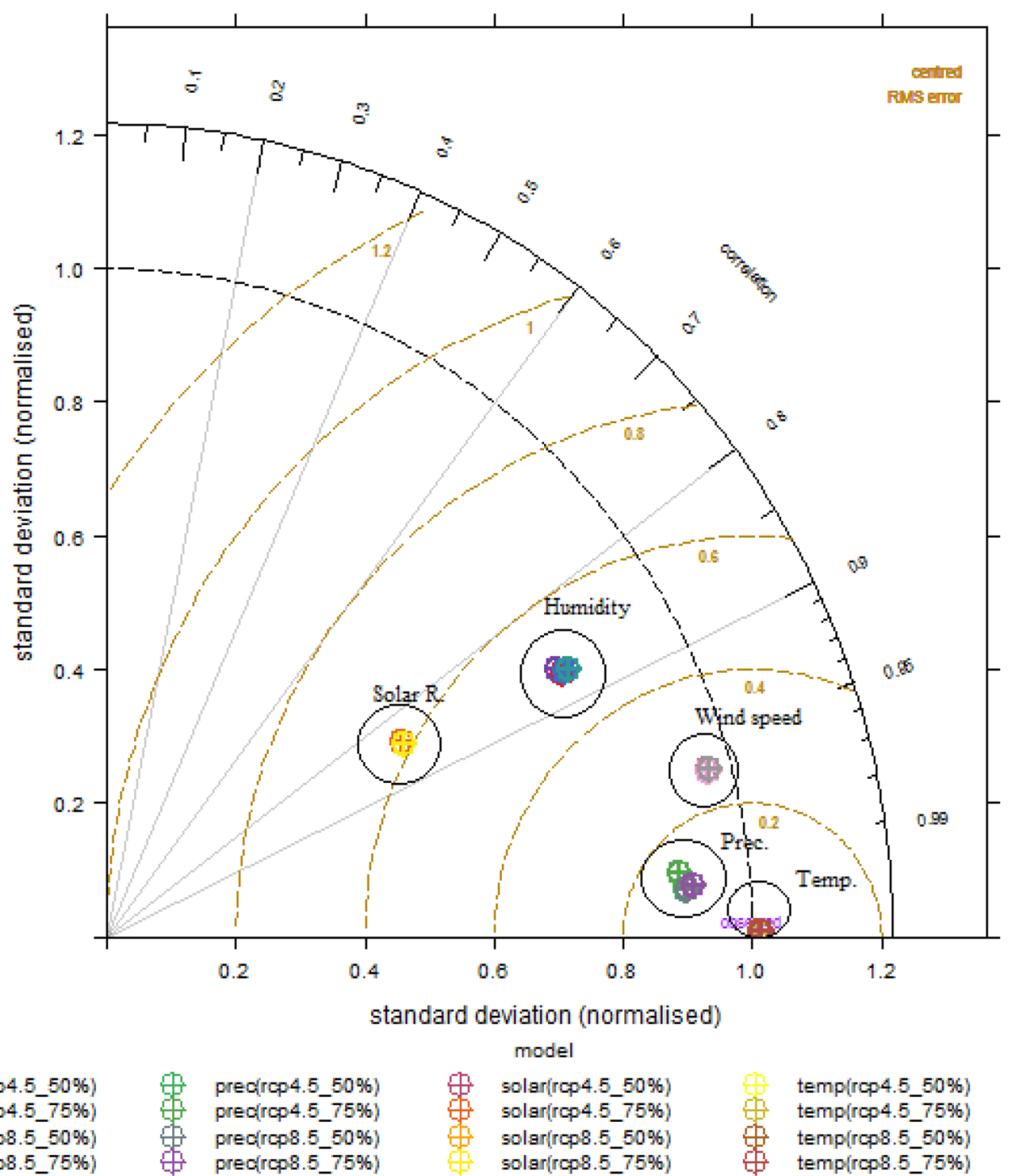

wind (rcp4.5_50\%) wind(rcp 4.5_75\%) wind (rcp8.5_50\%)

Fig. 3 Taylor diagram for the mean temperature, precipitation, wind speed, solar radiation and relative humidity of each forced RCP for the median $(50 \%)$ and 3rd quartile $75 \%$ ensembles. The horizontal and vertical axes represent the ratio of the standard deviations of the reference and simulated fields. The radial axis indicates the spatial correlation between the reference and simulated fields. The distance between the origin and any point is proportional to the RMSE 
change projections obviously depend on the climate model results, the scientific community have set up an international project to compare these models. The various phases of the CMIP have grown steadily as testified both in terms of participants' number and scientific impacts (Dufresne et al. 2013).

The River Shannon, the focus of this study, is the largest transboundary river system and catchment in the island of Ireland and one of the most important water and power resources in the Republic of Ireland. The Shannon river basin district (Fig. 1), defined according to the objectives of Water Framework Directive (Directive 2000), includes an area of about $18,000 \mathrm{~km}^{2}$ and covers around $20 \%$ of Ireland island, mostly in the lowland central area of the Republic of Ireland but with a small part $\left(6 \mathrm{~km}^{2}\right)$ of the upper River Shannon basin extending across the border to Northern Ireland. It has been estimated that there are more than 1600 lakes in the river basin district. The area includes about $73 \%$ agricultural land and $12 \%$ wetland, mostly peatland habitat (McCarthy et al. 2008, Gharbia et al. 2016; Assessment 2012, 2013).
The River Shannon (Fig. 1) drains an area of approximately $11,700 \mathrm{~km}^{2}$, before flowing into the sea at Limerick. The gradient is remarkably low, with the river rising at about $152 \mathrm{~m}$ above sea level and then flowing southwards with only a $12-\mathrm{m}$ drop in altitude over $185 \mathrm{~km}$, before finally descending more rapidly to sea level (Gharbia et al. 2016; Assessment 2012, 2013; McCarthy et al. 2008). The potential impacts of climate change are of most concern where water resources are either heavily allocated or particularly vulnerable to changes in rainfall (Kulkarni et al. 2011), in addition to risks due to extreme events (Engler and Werner 2015). In the Shannon catchment, the possibility of reduction in water availability or the possibility of future flooding scenarios as result of higher intensity rainfall events (due to climate change) may affect surface water and groundwater use which can severely impact upon human life and livelihoods. This therefore gives a strong justification to choose the Shannon as a study area.

In this study, climate change projections for the Shannon River catchment will be presented for several climate variables (temperature, precipitation, wind speed, solar

Table 3 Monthly absolute values box-whisker plots for each predicted year and baseline variables

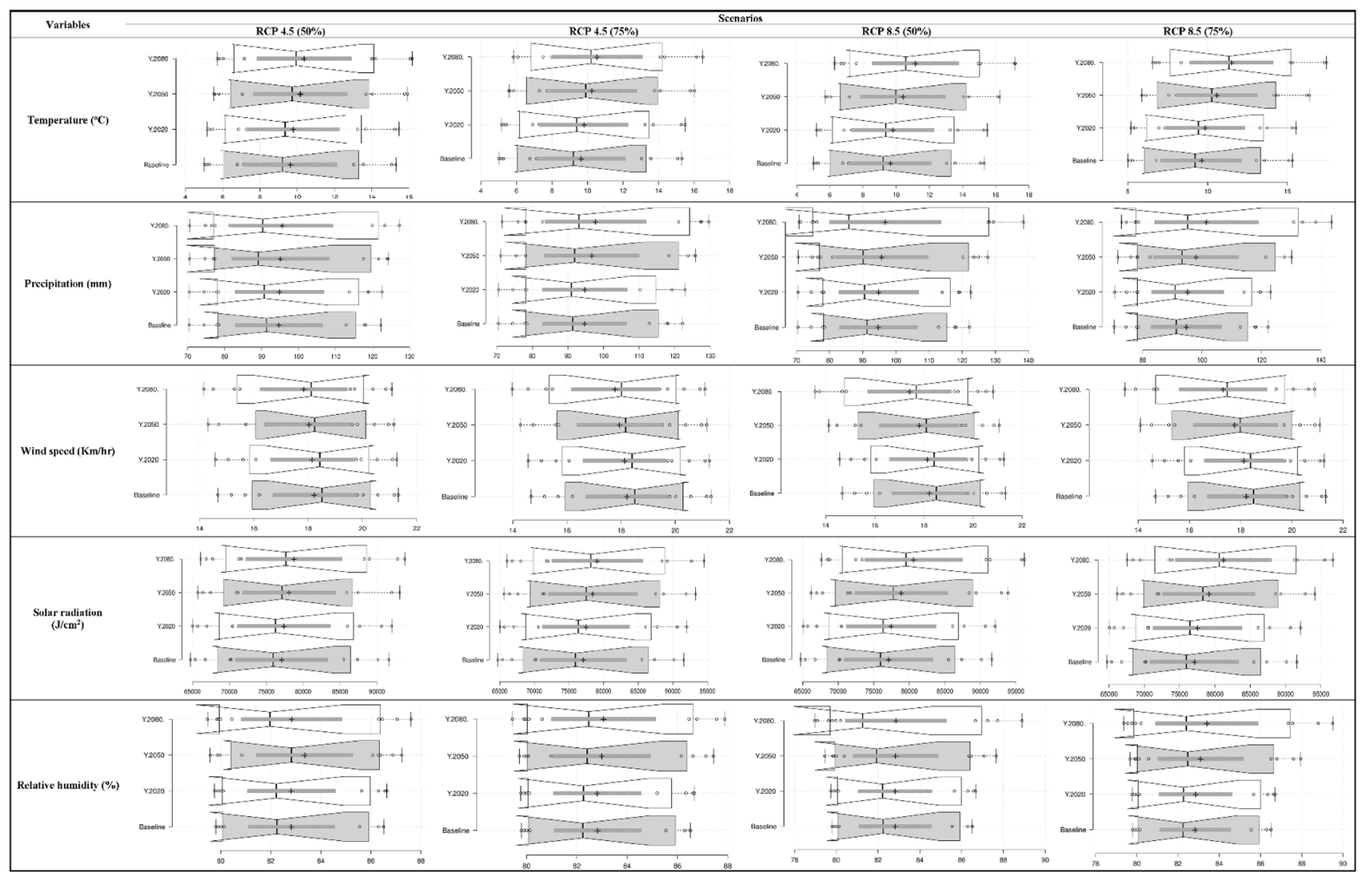

Center lines show the medians; box limits indicate the 25 th and 75 th percentiles as determined by R software; whiskers extend 1.5 times the interquartile range from the 25 th and 75 th percentiles, outliers are represented by dots; crosses represent sample means; bars indicate $95 \%$ confidence intervals of the means; data points are plotted as open circles 
radiation and relative humidity) from multi-GCM ensembles for three future time intervals using a range of different representative concentration pathways (RCPs) (Moss et al. 2010). This paper presents the innovative use of a geographical information system (GIS) as a downscaling environment, which is unprecedented in literature. The projection process used a statistical downscaling procedure based on statistical relationships linking a set of large-scale atmospheric variables to regional climate variables in an observational calibration period. After a particular verification and performance evaluation using several techniques (such as the Taylor diagram for each GCM-ensemble within independent sub-periods), the established statistical relationships were used to predict the response of future regional climates from the simulated changes to the large-scale variables in the climate model. This paper aims to present GIS platform as a downscaling environment through a suggested algorithm, which applies statistical downscaling models to multidimensional GCMEnsembles simulations. Applying such algorithm on GIS platform provides a wide range of output formats for the datasets, which can be used in most of the impact models without any extra effort in formatting the output datasets.

\section{Materials and methods}

As shown in the general framework flowchart in (Fig. 2), multi-stage formulation modelling was carried out entirely within the GIS environment in order to evaluate the performance of climate model multi-GCM ensembles and thereby adequately describe the future climate over Shannon river basin. A GIS-based python algorithm was developed to implement downscaling and the performance evaluation, which is described in this section.

A set of weather variables (temperature, precipitation, wind speed, solar radiation and relative humidity) were downscaled from climate change models at high quality resolution (cell size $50 \mathrm{~m} \times 50 \mathrm{~m}$ ) from the GIS model and projected to three future time periods, the 2020s, 2050s and

Table 4 Monthly differences from baseline values box-whisker plots for each year of predicted variables

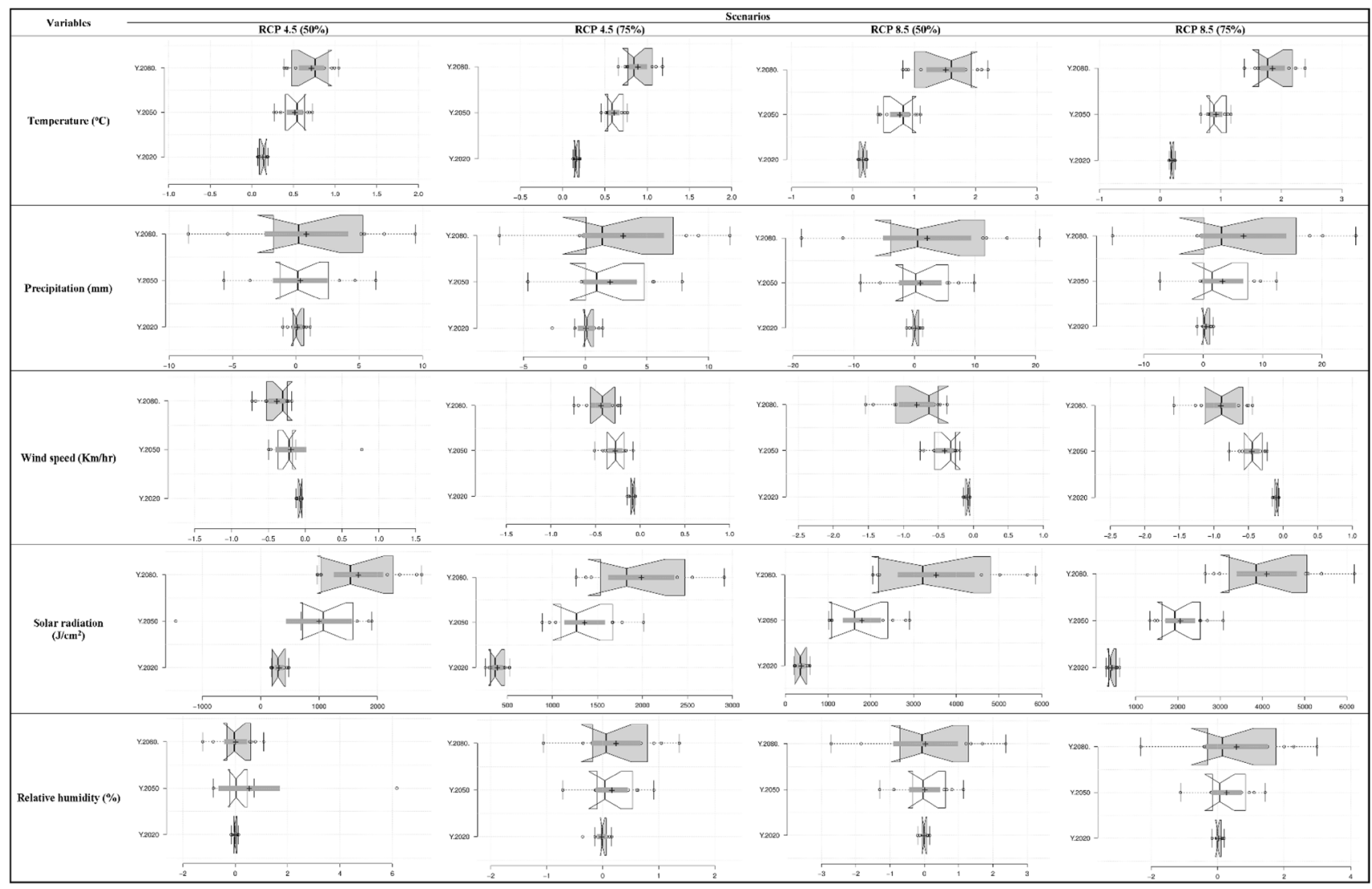

Center lines show the medians; box limits indicate the 25th and 75th percentiles as determined by R software; whiskers extend 1.5 times the interquartile range from the 25th and 75th percentiles, outliers are represented by dots; crosses represent sample means; bars indicate $95 \%$ confidence intervals of the means; data points are plotted as open circles 
2080s. Climate change models based on two different RCPs (using radiative forcing of 4.5 and $8.5 \mathrm{~W} / \mathrm{m}^{2}$, respectively) were produced from median and 3rd quartile simulation results of multi-GCM ensembles. These ensembles simulations were calculated from the overlay process for GCMs datasets after fixing the temporal scale for each GCM to a monthly time scale. The median and 3rd quartile simulation results were used because it was recommended in the literature that these simulations have the optimal minimum uncertainty in projections of risk from climate change (Araújo et al. 2005). The performance evaluation process for climate model results using the Taylor diagram and different statistical tests then lead to the development of high spatial resolution projected maps for temperature, precipitation, wind speed, solar radiation and relative humidity.

This section presents the data, methods and the developed GIS-based python algorithms used in the downscaling procedure.

\section{Model data}

Observed daily data for precipitation, temperature, wind speed, solar radiation and relative humidity were obtained from all available stations (96 station) in the Shannon Catchment from the national Irish meteorology organisation (Met Éireann), for the period 1961-2014 (Fig. 1). The selected stations are generally at low elevations and can be considered of high quality, data being collected by experienced meteorological officers. Although there were some missing readings in the data, their number were not so large as to be statistically significant and so they were excluded from the data set used. For baseline calculation purposes, data from 1961 to 2000 were used and the remaining data from 2000 to 2014 were used for the calibration and evaluation processes.

Large-scale surface and atmospheric data were obtained from the datasets of the International Centre for Tropical Agriculture (CIAT) and the CGIAR Research Program on Climate Change, Agriculture and Food Security (CCAFS) (Mitchell and Osborn 2005; Ramirez and Jarvis 2008; Wilby and Wigley 1997). Standardised reanalysis variables were then used as candidate predictor variables to calibrate the transfer functions, linking the large-scale surface and atmospheric variables to the observed stations data.

GCM data were obtained, for five models from the Hadley Centre, Canadian Centre for Climate Modelling and Analysis, Centre for Climate Research in Japan, the Commonwealth Scientific and Industrial Research Organization and National Centre for Atmospheric Research, USA for both representative concentration pathways RCP 4.5 and RCP 8.5. The datasets exist on grid resolutions as illustrated in Table 1, and were obtained for the grid box representing Ireland in the GCM domain. These GCMs

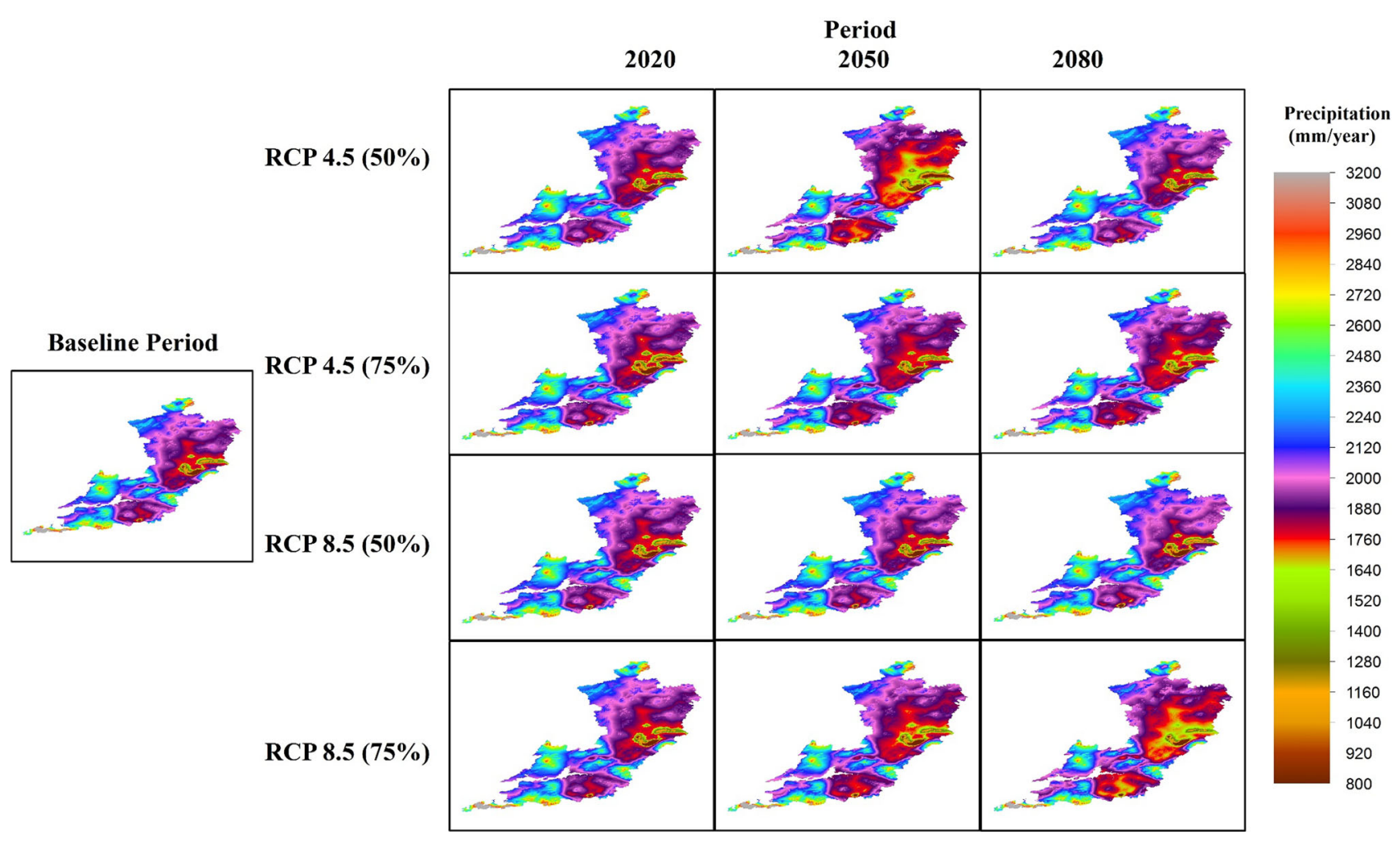

Fig. 4 Precipitation long-term average for the baseline and projection periods according to different representative concentration pathways 
have been chosen because they have been used individually before in UK and Ireland and because they have the smaller spatial grid size among the available GCMs.

\section{Selecting representative concentration pathways (RCPs)}

The RCPs are four greenhouse gas concentration trajectories adopted by the IPCC for its Fifth Assessment Report (AR5) (Stocker et al. 2013b). The four RCPs, RCP2.6, RCP4.5, RCP6.0, and RCP8.5, are named after a possible range of radiative forcing values in the year 2100 of 2.6, $4.5,6.0$, and $8.5 \mathrm{~W} / \mathrm{m}^{2}$, respectively. RCPs are defined as follows: peaks in radiative forcing at $3 \mathrm{~W} / \mathrm{m}^{2}$ before 2100 and decline for RCP 2.6; stabilization without overshoot pathway to $4.5 \mathrm{~W} / \mathrm{m}^{2}$ at 2100 for RCP 4.5 ; stabilization without overshoot pathway to $6 \mathrm{~W} / \mathrm{m}^{2}$ at 2100 for RCP 6.0 ; and rising radiative forcing pathway leading to $8.5 \mathrm{~W} / \mathrm{m}^{2}$ in 2100 for RCP 8.5 (Riahi et al. 2007; Kurosawa 2004; Clarke et al. 2007; Smith and Wigley 2006; Whetton et al. 2006; Van Vuuren et al. 2007, 2011).

Modelling the response for any environmental system according to changes makes more sense if the worst case and the middle case were used as forcing cases for modelling process. Hence, RCP 4.5 and RCP 8.5 were used in this study as forcing scenarios for climate models (Stocker et al. 2013b; Solomon 2007; Meinshausen et al. 2011, Taylor et al. 2009a; Kattenberg et al. 1996; Giorgi et al. 2001; New and Hulme 2000).

\section{Modelling procedures and downscaling}

Although global simulations indicate coarse grid patterns of change associated with natural and anthropogenic climate forcing, they cannot capture the detailed effects of narrow mountain ranges, complicated land/water interactions, or variations in land-use. Statistical or empirical downscaling is an alternative approach for obtaining regional-scale climate information from large-scale simulations to bridge the gap between global climate models and local impacts. Statistical downscaling has an important advantage over a regional model or dynamical downscaling: it is computationally efficient and allows the consideration of a large set of climate scenarios. However, statistical downscaling of future climate scenarios must be based on predictors that can capture the effects of climate change, and not just of climate variability. The main idea behind statistical downscaling is to use statistical relationships to link resolved behaviours in GCMs with the climate in a study area. This approach encompasses a range of statistical techniques as simple linear regression, delta change method, multiple regression, weather generators, canonical correlation analysis

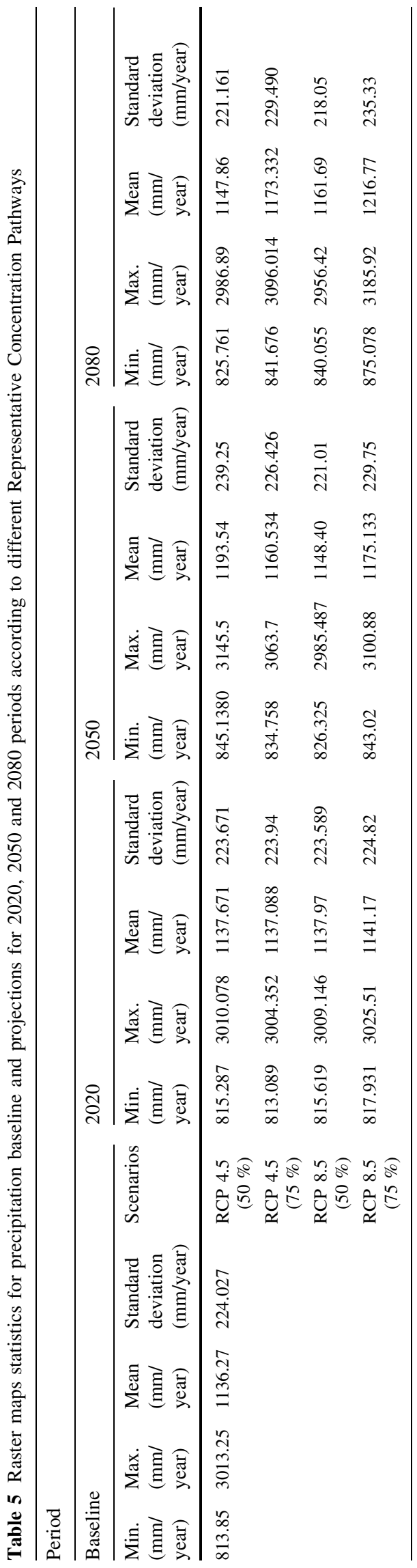


and artificial neural networks (Salathe et al. 2007; Kattenberg et al. 1996; Giorgi et al. 2001; Hewitson and Crane 2006; Joubert and Hewitson 1997; von Storch et al. 1993; Crane and Hewitson 1998).

The GIS based approach proposed in this paper employed statistical downscaling; in specific, two different techniques were used according to the suitability to the targeted climatic datasets:
1. The delta change method was used to downscale temperature and precipitation because of the high quality data and continuous readings for these datasets;

2. Multiple regression models were used to predict wind speed, solar radiation and relative humidity using both the temperature and precipitation predictands for each model in order to prevent the uncertainty related to some missing readings in the same predictors data.

Fig. 5 Average precipitation (mm/year) changes from the baseline period for each simulated scenario over the Shannon catchment
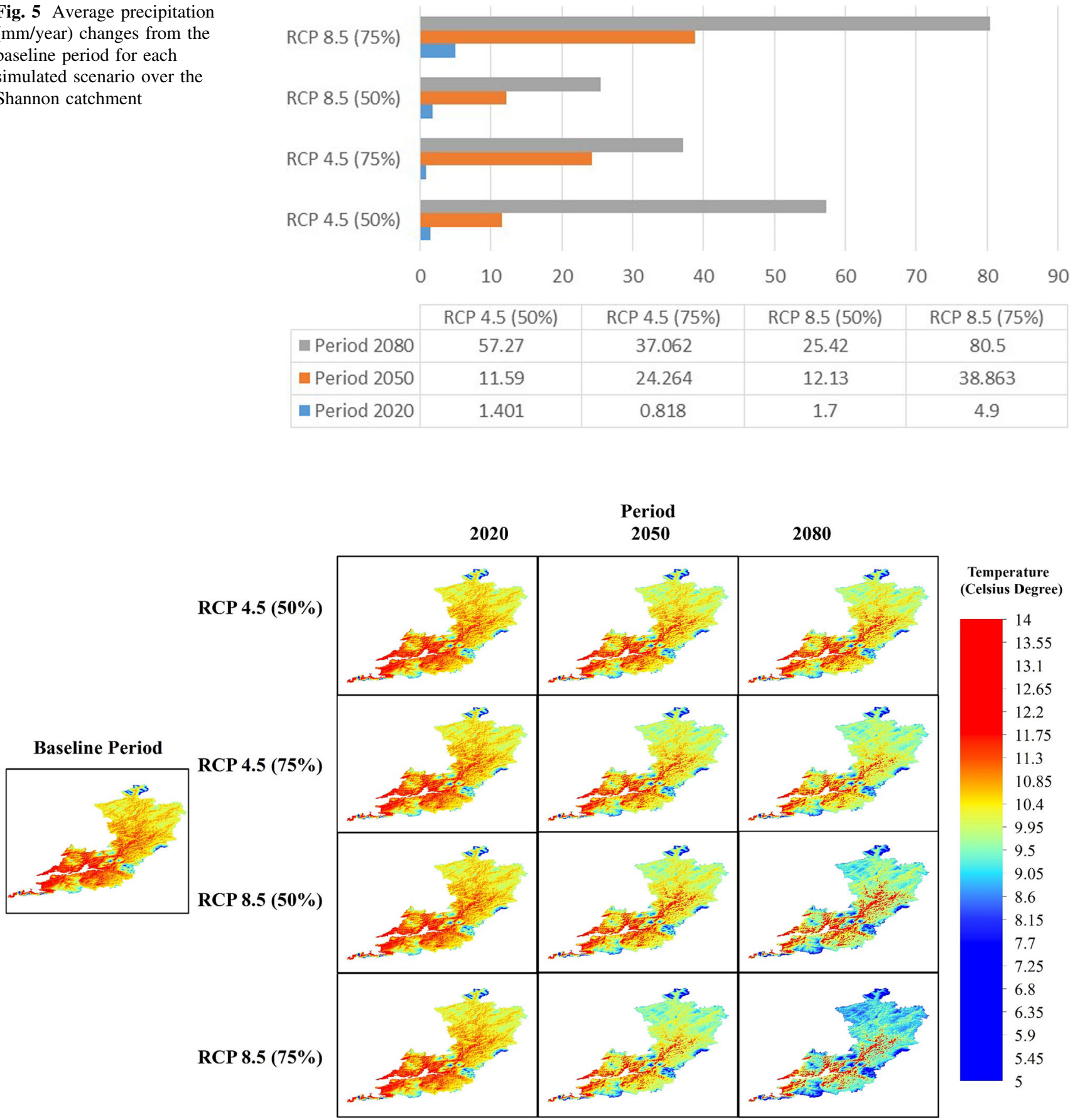

Fig. 6 Temperature long-term average for the baseline and projection periods according to different representative concentration pathways 


\section{GIS-based python algorithm}

This paper presents a GIS-based python algorithm for GCM-Ensembles downscaling and performance evaluation simulations. This algorithm uses GIS as the platform for the simulation process through spatial geo-processors. The algorithm loops through a process to downscale the climate variable and evaluate the performance of the designed GCM-ensemble experiment. The observed weather data for Shannon, GCMs data and the selected RCPs are employed as a case study for different experiments using this GISbased algorithm.

The algorithm spatial simulation steps are as follow:

1. Choose the GCMs that participated in the ensembles, as described in the previous Sections.

2. Choose the forcing RCPs targeted for each experiment, as described in Sect. 2.2.

3. Feed the multidimensional files for each global model experiment into the algorithm, as based on the GCMs simulation data.

4. Calculate the mean temporal scale for each simulated multidimensional file of each GCM experiment, in order to fix the temporal resolution between all the experiments that participated in the ensemble, (i.e. all GCMs were set to a common monthly temporal scale).

5. Resample the grid size for each gridded file result from each experiment to unify the large scale resolutions, in order to have the same pixel size for each gridded file per experiment.

6. Overlay, a spatial operation in which two or more grids registered to a common coordinate system are superimposed for the purpose combine them in the same tabulated dataset, the simulated grids for all GCMs that participated in the experiments.

7. Run a sub-algorithm for the geo-statistical simulation for each experiment in order to calculate the two targeted grids weights [50\% (median) and $75 \%$ ensembles]. Different GCMs produce several regional climate results even when run with the same emissions data (Stocker et al. 2013a; Solomon 2007; Meinshausen et al. 2011; Taylor et al. 2009a; Kattenberg et al. 1996; Giorgi et al. 2001; Hulme and Carter 1999), however, many impact studies employ only one climate change scenario, based on one emissions scenario, derived by single GCM. From a risk assessment perspective this could be considered unsound. Ensembles or weighting of the downscaled results, were used in this GIS-based algorithm to overcome this risk in climate change projections. This ensembles or weighting was based on the individual GCM's ability to reproduce the properties of the observed climate. The modified

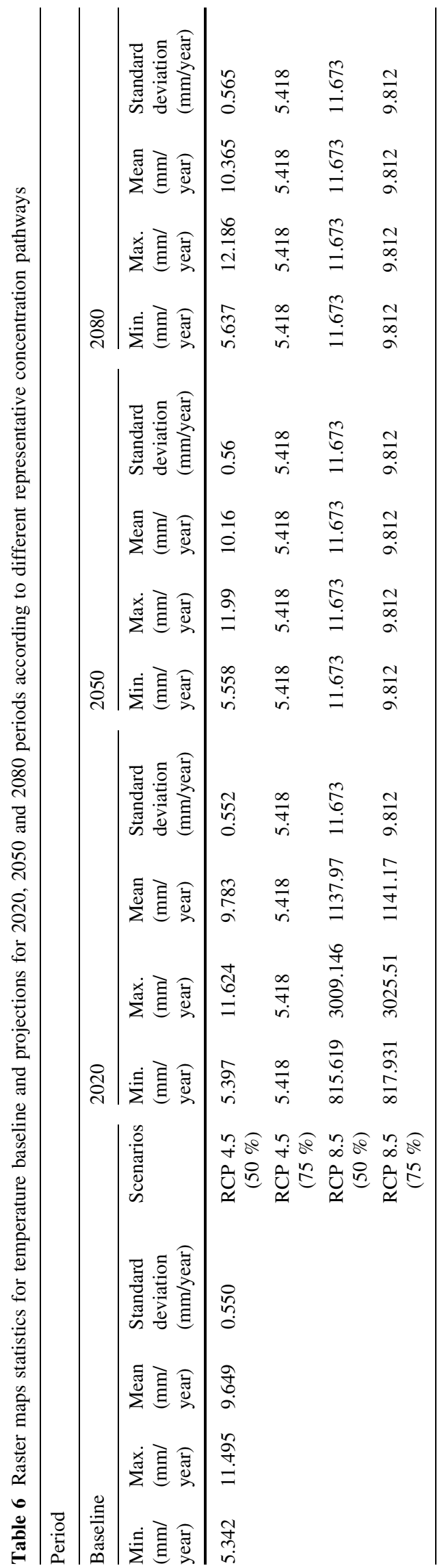


impacts relevant climate prediction index is weighted based on the individual GCMs ability to reproduce the properties of the observed climate and is derived from the root-mean-square difference between modelled and observed climatological data (Hulme and Carter 1999; Wilby and Harris 2006), median and 75 percentile (3rd quartile), assessed over the baseline period. The median and 75 percentile ensembles, produced from the weighted median and 75 percentile results for multi-GCM described above, were developed for Shannon catchment and assessed over the baseline using the developed GIS-based algorithm.

8. Choose the downscaling method for each climatic variable in each experiment. In this case study, the GIS-based algorithm that was developed applies the delta change method and multiple regression models as selected statistical downscaling methods under GIS platform. The delta method or change factor is the ratio between GCM simulations of future and current climate with resepct to precipitation and it is the difference between GCM simulations of future and current climate with respect to temperature. It is used as a multiplicative factor to obtain future regional conditions so that the differences between the control and future GCM simulations are applied to baseline observations by adding or scaling the mean climatic to each time step. The method assumes that GCMs more accurately simulate relative change more than absolute values. In addition, the change factors only scale the mean, maximum and minimum of the climatic variables, ignoring changes in variability and assuming the spatial pattern of climate will remain constant. In the delta change method, the predictor is the currently observed value for the same predictand variables. The predictor multiplies with the change factor, which is the ratio between the simulated values from the GCM output for the current period and the future. More generally, the predictor and predictand need to be the same variable (Fowler et al. 2007;
Fig. 7 Average temperature $\left({ }^{\circ} \mathrm{C}\right)$ changes from the baseline period for each simulated scenario over the Shannon catchment

Fig. 8 Average solar radiation $\left(\mathrm{j} / \mathrm{cm}^{2}\right)$ changes from the baseline period for each simulated scenario over the Shannon catchment

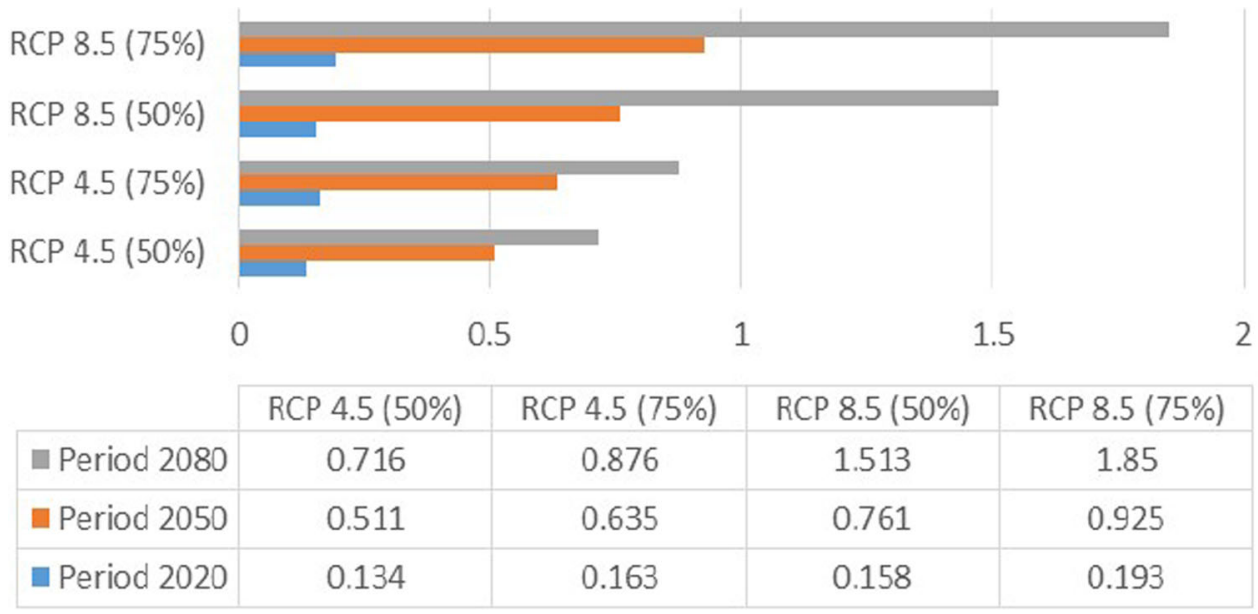

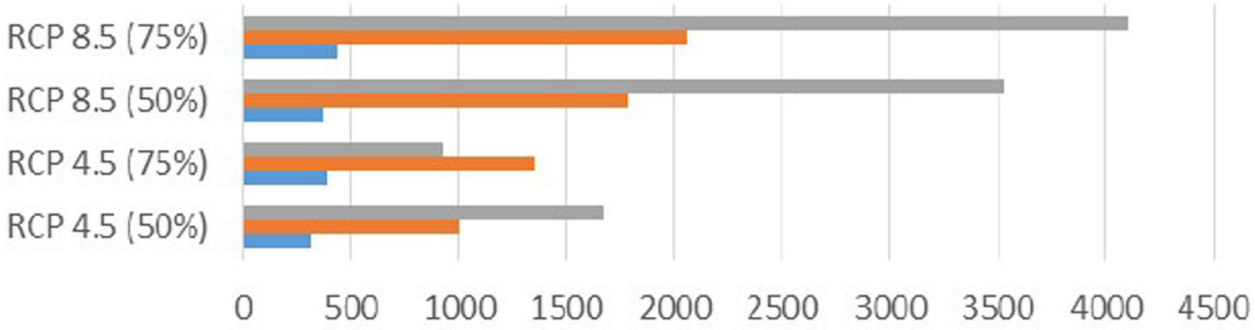

\begin{tabular}{|c|c|c|c|c|}
\hline & RCP $4.5(50 \%)$ & RCP $4.5(75 \%)$ & RCP $8.5(50 \%)$ & RCP 8.5 (75\%) \\
\hline Period 2080 & 1673.3 & 929.86 & 3532 & 4104.8 \\
\hline Period 2050 & 999.55 & 1358.87 & 1792.04 & 2056.64 \\
\hline Period 2020 & 314.9 & 388.95 & 372.19 & 440.54 \\
\hline
\end{tabular}


Prudhomme et al. 2002; Diaz-Nieto and Wilby 2005; Hay et al. 2000). Transfer function is a term used to describe methods that directly quantify a relationship between the predictand and a set of predictor variables (Giorgi et al. 2001). Multiple regression models are constructed using grid cell values of atmospheric variables as predictors for the surface climatic variables. There have been a number of recent innovations in this type of downscaling method such as the use of a logistic regression model for daily precipitation probability and a generalized linear model to predict the number of wet days in the Ebro Valley in Spain (Abaurrea and Asín 2005). Multiple regression models exist when there are two or more predictor variables (such as coarse gridded rainfall and temperature), which act as the input signal for the regional climate. A method called forwarded selection is the most common method used to establish a multiple regression equation in which the predictor variable that explains the most variance is first identified. The remaining variables are then classified and the variable that most reduces the remaining variance is selected. This method has been used which has resulted in relative humidity, solar radiation and wind speed variables being eliminated from regression models and it has been concluded that the temperature and precipitation variables should be used in the regression models. This procedure is repeated in order to get the most appropriate variable until no further improvement is obtained. The most essential assumption behind the regression models is that they are symmetrically distributed around the mean or normally distributed without any skew (Hay and Clark 2003; Zorita and Von Storch 1999).

9. Run a sub-algorithm for the selected downscaling method for the specific experiment with the observed data as input.

10. Evaluate the results for each experiment through statistics and Taylor diagram.

\section{Results and discussions}

\section{Validation and performance evaluation}

In order to validate the climate models results, observed data for each modelled climate variable for the 1961-2014 periods were used for the validation process. High correlations were obtained for climate models validation as shown in Table 2 which illustrated statistical tests results $\left(\mathrm{R}^{2}\right.$ values) for all modelled variables for the Shannon

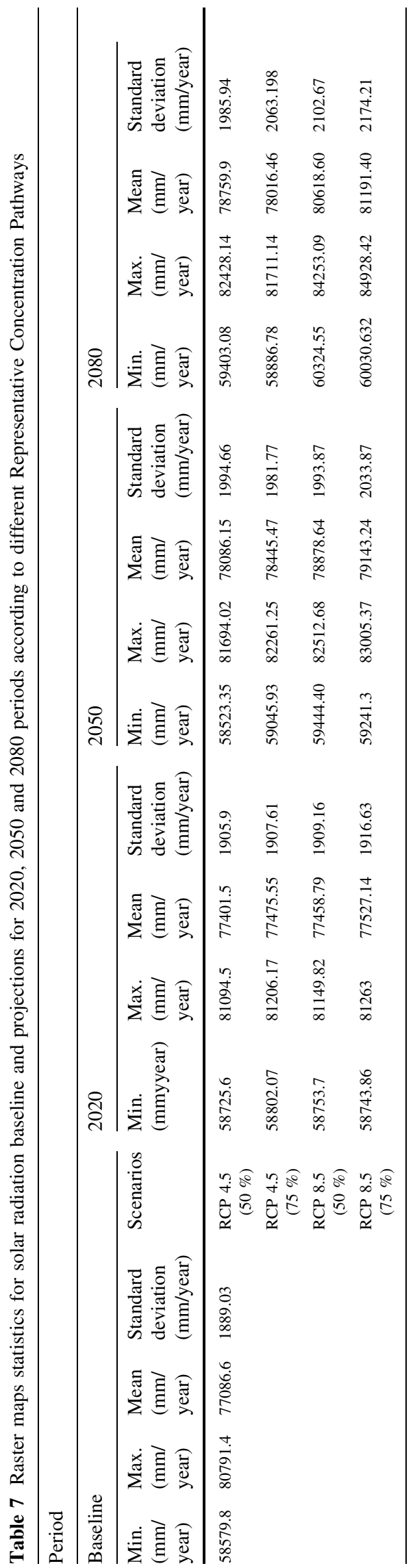


catchment. These statistics are for monthly time steps and averaged for all stations.

For the climate models and ensembles performance evaluations, Taylor diagrams and box-whisker plots have been prepared for each modelled monthly climate variable. Taylor diagrams (Taylor 2001) provide an efficient way of graphically summarizing how closely a model or ensemble fits observations. The similarity between two patterns is quantified in terms of their correlation, their root-meansquare difference and the amplitude of their variations. In this paper Taylor diagrams have been used to validate and evaluate the performance of climate models and their ensembles predictions.

In the Taylor diagram (Fig. 3), statistics for 20 models were computed with a coloured point assigned to each model. The position of each point appearing on the plot quantifies how closely the model's simulated results match the observations. First of all, it can be seen that the pattern correlations are generally high (higher than 0.7 in all cases). Secondly, one can notice that the variance is generally underestimated by the models, whatever the climatic variable, RCP or ensemble. This was actually expected from the high values of R-square for the validation period. It is also interesting to note that there is high coherence between the models: i.e. they share similar qualities or deficiencies (see the clusters of colour points for each climatic variable).
Also for the multi-GCM ensembles performance evaluation, (Tables 3, 4) were developed for each projected climatic variable and for each climate scenario for both absolute values and changes from baseline values, respectively. Each table has 20 box-whisker diagrams in which the centre lines show the medians, the box limits indicate the 25th and 75th percentiles as determined by R software, the whiskers extend to 1.5 times the interquartile range from the 25th and 75th percentiles, outliers are represented by dots, crosses represent sample means, bars indicate $95 \%$ confidence intervals of the means, and notches are defined as $\pm 1.58 \times$ inter quartile range/sqrt (n) and represent the $95 \%$ confidence interval for each median. Non-overlapping notches give $95 \%$ confidence that two medians are different. It is clear that the absolute values and the changes from baseline values for each climate variable increase with increasing projected years and by moving from left to right in each table from RCP 4.5 (50\%) to RCP 8.5 $(75 \%)$. This is valid for all variables except wind speed.

\section{Climate change projections}

So far, the studies in literature addressing climate change downscaling in Ireland have used only one GCM (Ellis et al. 2007; Wang et al. 2006; Sweeney et al. 2003; Lindner et al. 2010; Bastola et al. 2011; Araújo et al. 2005; Berry et al. 2002) and the IPCC forth assessment report (AR4) emission scenarios (Change, 2007; Pachauri and Reisinger

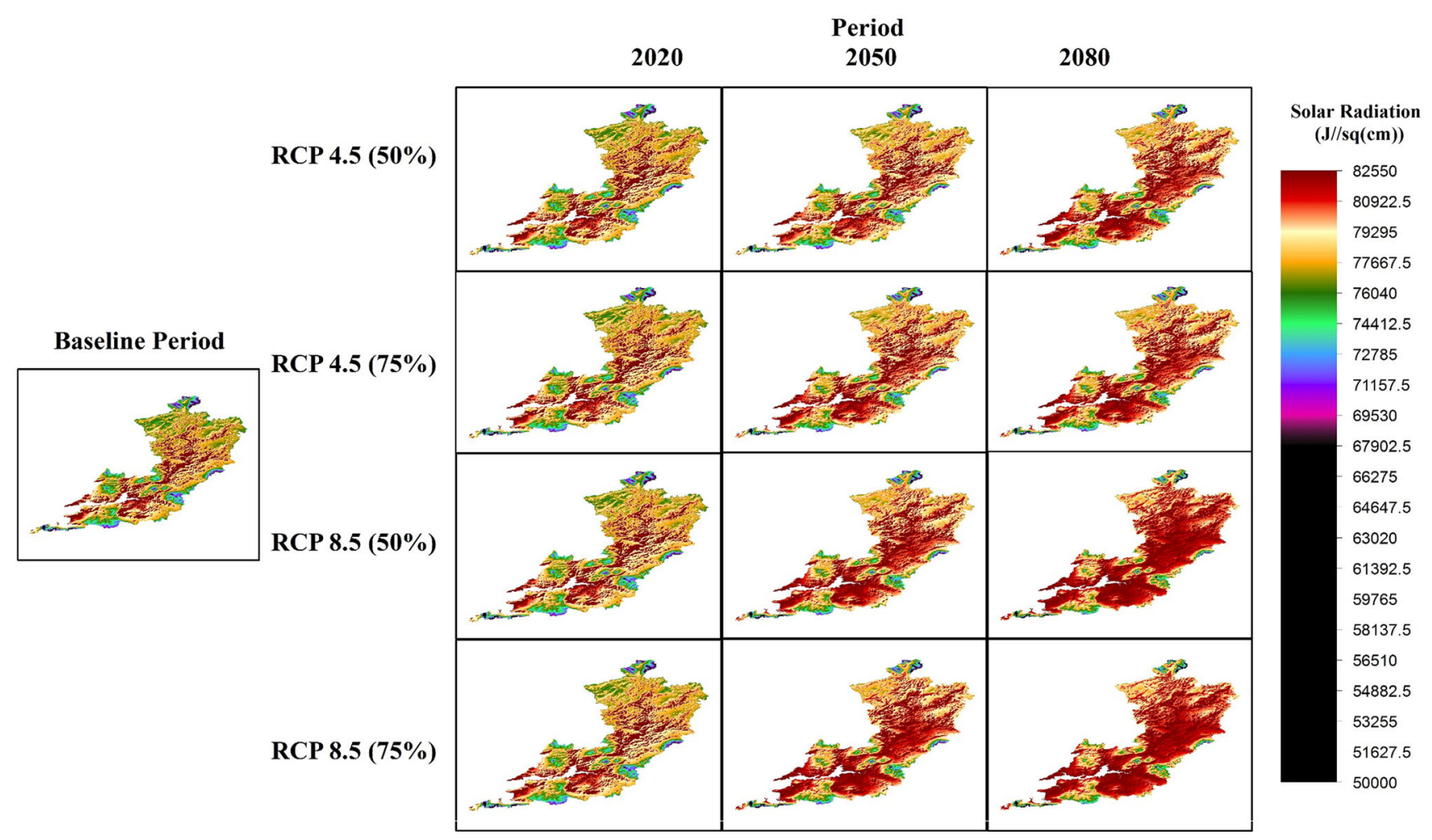

Fig. 9 Solar radiation long-term average for the baseline and projection periods according to different representative concentration pathways 

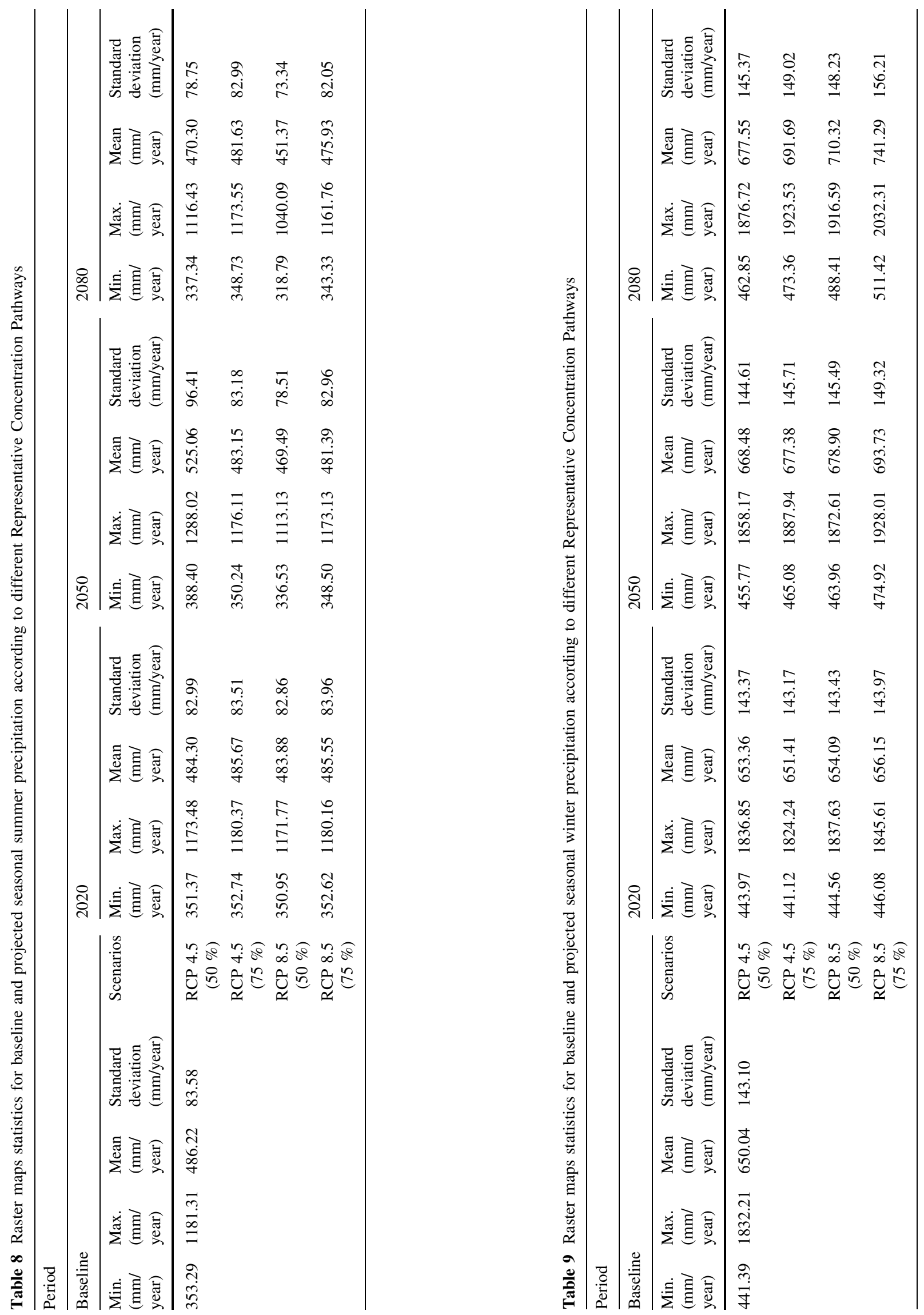

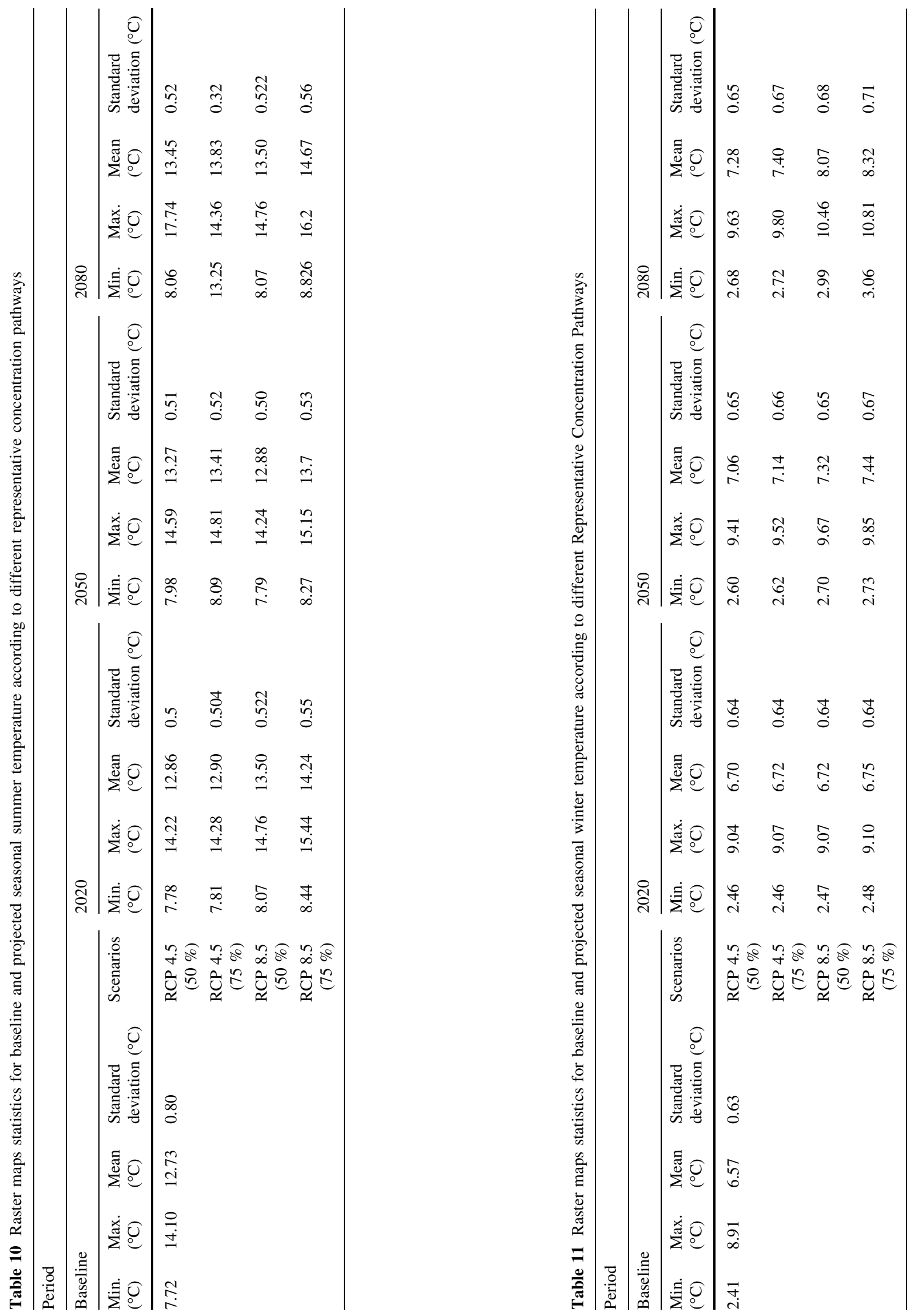


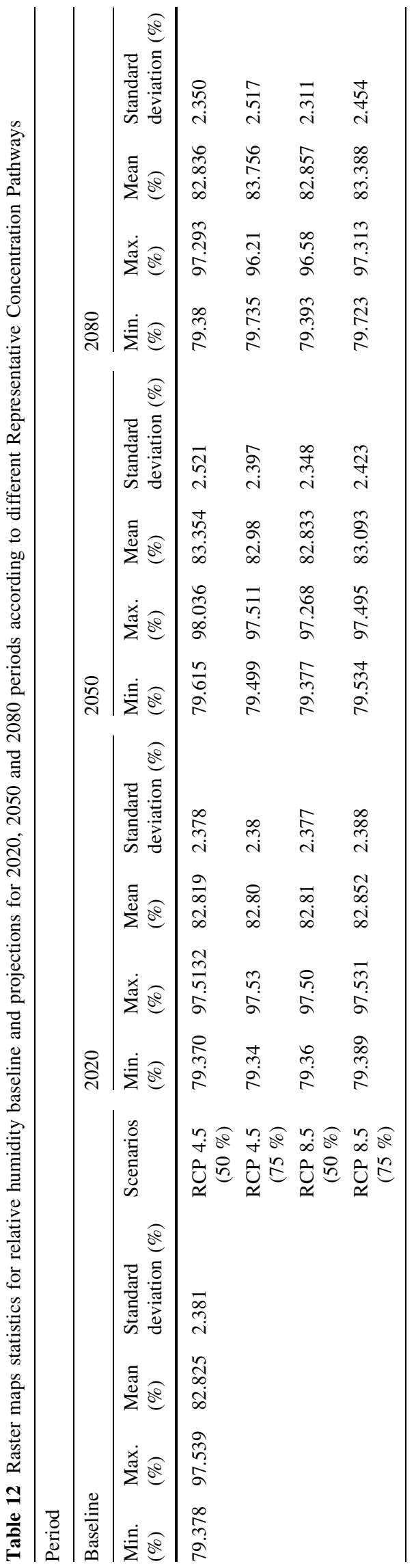

2007). It also should be noted that these studies completed the downscaling using a coarse resolution and they did not address such a wide range of climate variables as presented in this research. Fealy and Sweeney (2008) illustrates one technique for downscaling GCM output for a selection of sites in Ireland using a weighted ensemble mean, derived from multiple GCMs for a high emissions scenario (A2). The study acknowledges inherent weaknesses due to lack of performance evaluation for the downscaling method. It also uses one AR4 emission scenario without any comparison with other scenarios and it ignores the need for a fine scale resolution results. In this paper, in addition to a performance evaluation for the used methodologies and GIS platform, the obtained projections are presented for the future climate over the river Shannon catchment. In this section, climate projections for three time intervals 2020, 2050 and 2080, which refers to 12 months in each period, (a summary of 1275 high-resolution $(50 \mathrm{~m} \times 50 \mathrm{~m}$ ) resultant maps, 255 for each climate variable including the predicted seasonal maps for each climate variable) were illustrated and compared with the baseline period (19612000), in order to assess the differences and changes in climate for temperature, precipitation, solar radiation, relative humidity and wind speed. Four different scenarios, RCP ensembles (RCP 4.5 (50\%), RCP 4.5 (75 \%), RCP $8.5(50 \%)$ and RCP $8.5(75 \%)$ were used to force these results, as discussed previously.

\section{Precipitation}

The spatial variation of precipitation is influenced by many different natural aspects such as elevation. Precipitation time series grids were derived by averaging gridded data over the Shannon catchment according to different scenarios and ensembles, as previously discussed. Figure 4 shows series of projected high-resolution precipitation maps for the Shannon catchment and Table 5 shows quantitative statistics for each map. Trends in precipitation show greater regional variation than temperatures, with occasional conflicting trends from stations which are geographically relatively close. However, there is evidence of an increase in the quantity of precipitation in general, as shown in Fig. 5, which illustrates that RCP 8.5 (75\%) would predict the highest future precipitation quantities over the catchment. Tables 8, 9 show seasonal precipitation raster maps statistics for baseline and projected periods according to different RCPs.

\section{Temperature}

Projected time series maps for temperature were compared with long-term observed temperature 1961-2014 and the results of the projected maps are shown in Fig. 6 and Table 6 with the mean changes in temperature from baseline period 
Fig. 10 Average relative humidity $(\%)$ changes from the baseline period for each simulated scenario over the Shannon catchment

\begin{tabular}{|c|c|c|c|c|}
\hline $\begin{array}{l}\mathrm{RCP} \\
\mathrm{RCP}\end{array}$ & $\begin{array}{l}5(75 \%) \\
5(50 \%)\end{array}$ & & & \\
\hline \multicolumn{5}{|c|}{$\begin{array}{l}\operatorname{RCP} 4.5(75 \%) \\
\operatorname{RCP} 4.5(50 \%)\end{array}$} \\
\hline \multirow[t]{2}{*}{-0} & 0 & 0.2 & 0.6 & 0.8 \\
\hline & RCP 4.5 (50\%) & RCP 4.5 (75\%) & RCP 8.5 (50\%) & RCP 8.5 (75\%) \\
\hline 080 & 0.011 & 0.931 & 0.032 & 0.563 \\
\hline 0 & 0.529 & 0.155 & 0.008 & 0.268 \\
\hline 020 & -0.006 & -0.025 & -0.015 & 0.027 \\
\hline
\end{tabular}

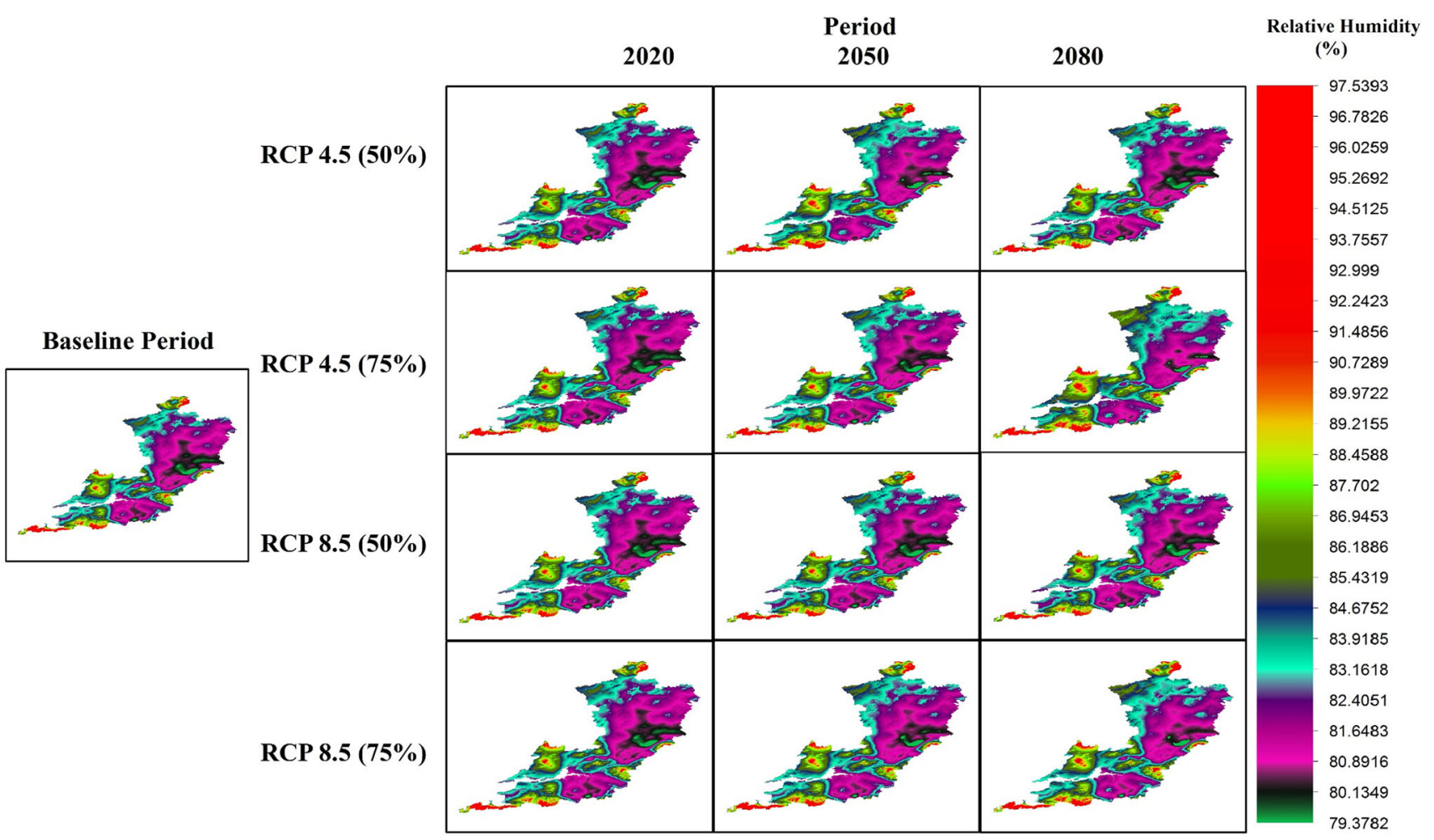

Fig. 11 Relative humidity long-term average for baseline and projection periods according to different representative concentration pathways

shown in Fig. 7. In general, the results for all the ensembles simulations show that temperature will increase every year. Again RCP $8.5(75 \%)$ has the highest increasing rate $\left(1.85^{\circ} \mathrm{C}\right.$ in 2080 as average over Shannon catchment), which is consistent with the global rise in air temperatures. All seasons show an increase in temperature with the highest increases occurring in the spring and summer. Tables 10, 11 show seasonal temperature raster maps statistics for baseline and projected periods according to different RCPs.

\section{Solar radiation}

As shown in Fig. 8, Table 7 and Fig. 9 for solar radiation, all simulations indicate that there will be a significant increase in solar radiation over the Shannon catchment with such an incremental increase obvious when moving from RCP 4.5 (50\%), RCP 4.5 (75\%), RCP 8.5 (50\%) to RCP 8.5 (75\%), respectively. 


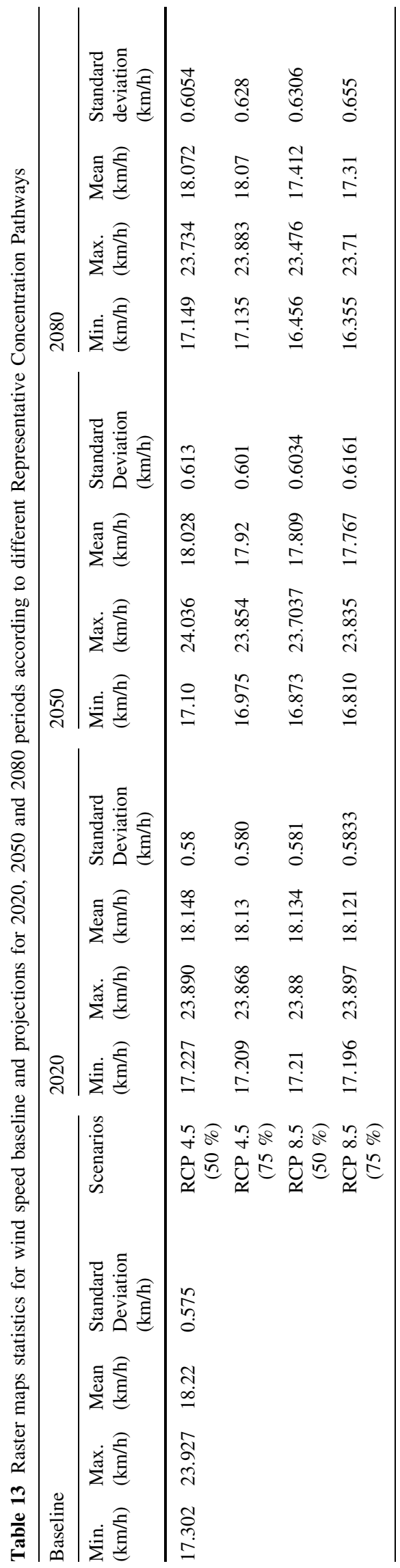

Relative humidity

The relative humidity simulation results are shown in Table 12, Figs. 10, 11, which all indicate a fluctuation in values but with slight increases dominant over the Shannon catchment. Again, predicted increases are clear when moving from RCP 4.5 (50 \%), RCP 4.5 (75\%), RCP 8.5 (50\%) to RCP 8.5 (75\%), respectively.

\section{Wind speed}

The wind speed simulation results shown in Table 13, Fig. 12, and Fig. 13 all indicate a fluctuation in values but with slight decreases in wind speed over the Shannon catchment. Again, this incremental decrease is clear when moving from RCP 4.5 (50\%) to RCP 4.5 (75\%) to RCP $8.5(50 \%)$ to RCP 8.5 (75\%).

\section{Conclusions}

This paper, in addition to performance evaluation for the methodologies and GIS platform used, presents the significant changes in temperature, precipitation, wind speed, solar radiation and relative humidity, which are projected for three future time intervals 2020, 2050 and 2080 using a multi model ensemble approach forced by AR5 RCPs.

This paper aims to present GIS platform as a downscaling environment through a suggested algorithm, which applies statistical downscaling models to multidimensional GCM-Ensembles simulations. Applying such algorithm on GIS platform provides a wide range of output formats for the datasets, which can be used in most of the impact models without any extra effort in formatting the output datasets.

This paper demonstrates the use of a GIS platform with raster data as a powerful multidimensional downscaling tool, which gives the ability to spatially link all the variables that participated in the downscaling process. The GIS platform also allows for the control of these links through the geo-statistical processors, in order to derive very fine scale data for future-projected changes in climate. The ability of using geo-statistical processors in a GIS platform is of crucial importance for the assessment process in complex hydrological systems (such as large catchments) to estimate how much confidence can be achieved in climate change projections and subsequent impact assessments.

There are many sources of uncertainty in climate projection studies. The main source is related to the GCM simulation and selection, which often needs to be taken into account. The study shows that the differences between ensembles mainly depend on the original GCMs that were 
Fig. 12 Average wind speed $(\mathrm{km} / \mathrm{h})$ changes from the baseline period for each simulated scenario over the Shannon catchment

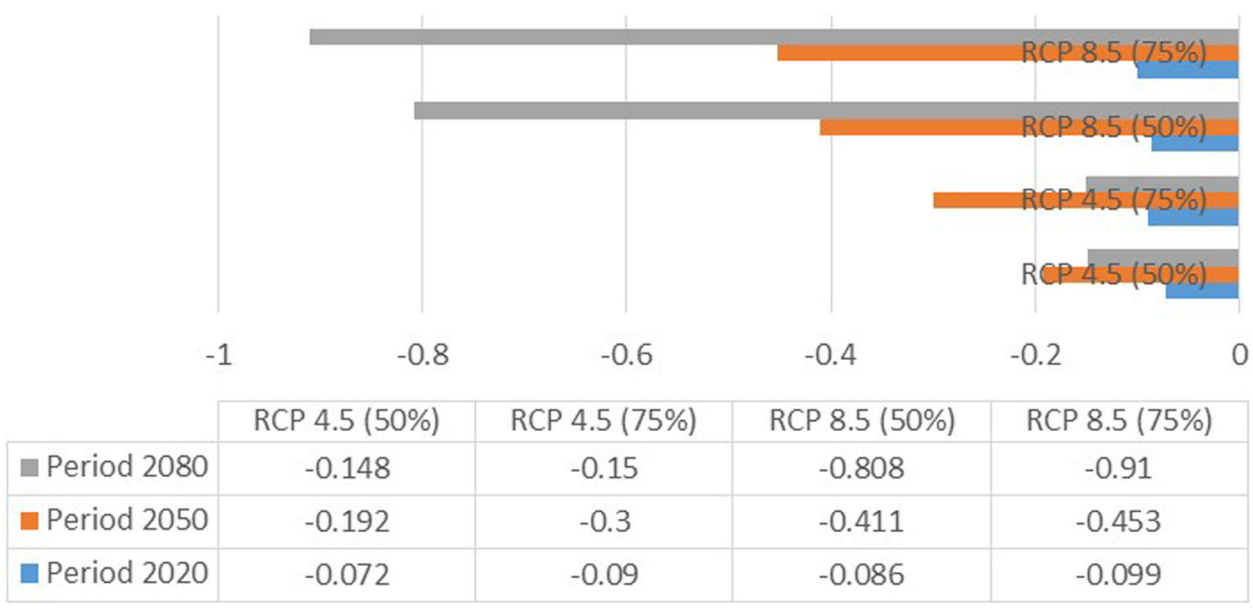

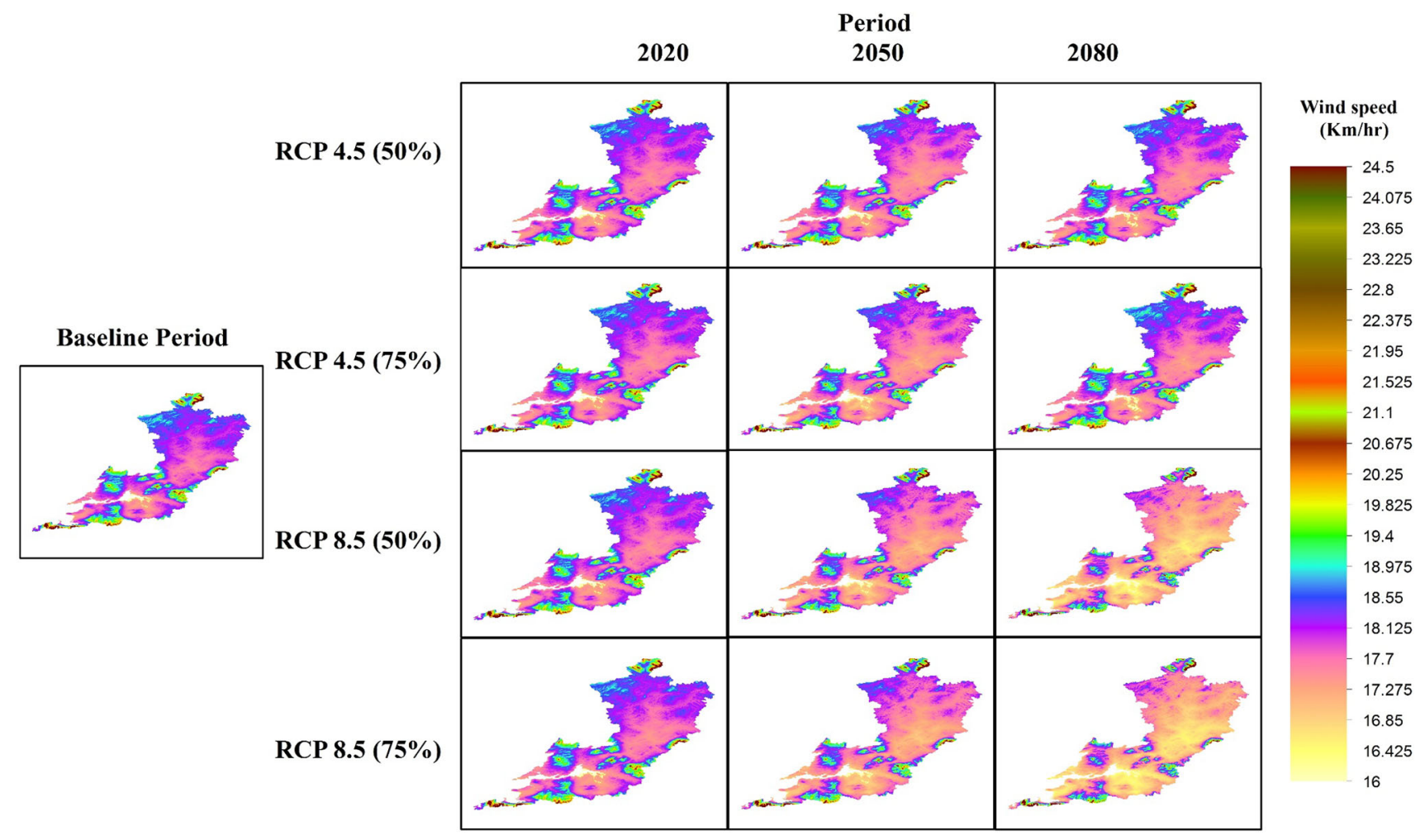

Fig. 13 Wind speed long-term average for baseline and projection periods according to different representative concentration pathways

used in the ensembles. In this study, the comparisons between ensembles forced by two different RCPs show that there are some agreements in the climate change signal simulation in the study area. However, it is not easy to locate the changes with spatial precision and accuracy especially for precipitation, which makes the use of such results for decision-making by relevant stakeholders and practitioners problematic.

The study shows that downscaling is a sensitive step when only one climate model is used for climate change simulations because of the wide uncertainty related to the choice of GCM. This paper suggests that multi-climate models should be applied as an ensemble under the GIS environment for climate change simulations, especially for hydrological impact studies, as the output results formats from the GIS platform can be used directly in the hydrological models, as raster or victor data formats.

Using a GIS platform as a downscaling environment gives the ability to capture different seasonality and spatial patterns within climate variables. For example, the study of 
temperature in this paper shows that there are important differences between the ensembles results, especially in summer months. These differences may be of interest because of how they affect the accuracy of simulations in hydrological models.

Generally, it can be concluded that the uncertainty related to the downscaling process is lower than the uncertainty related to the RCP selection. Further work is still needed in the area of climate projections using a GIS platform, especially in the context of linking climate change simulations with hydrological physical-based models.

Acknowledgments This research was funded by Trinity College, Dublin through the Postgraduate Ussher Fellowship Award.

\section{References}

Abaurrea J, Asín J (2005) Forecasting local daily precipitation patterns in a climate change scenario. Clim Res 28:183-197

Araújo MB, Whittaker RJ, Ladle RJ, Erhard M (2005) Reducing uncertainty in projections of extinction risk from climate change. Global Ecol Biogeogr 14:529-538

ASSESSMENT, S. C.-B. F. R. 2013. Hydrology Report Unit of Management 25/26 Draft Report

Assessment S, C.-B. F. R. 2012. Inception report-unit of management 28 Draft Final Report

Bastola S, Murphy C, Sweeney J (2011) The role of hydrological modelling uncertainties in climate change impact assessments of Irish river catchments. Adv Water Resour 34:562-576

Berry P, Dawson T, Harrison P, Pearson R (2002) Modelling potential impacts of climate change on the bioclimatic envelope of species in Britain and Ireland. Global Ecol Biogeogr 11:453-462

Boé J, Terray L, Habets F, Martin E (2007) Statistical and dynamical downscaling of the Seine basin climate for hydro-meteorological studies. Int J Climatol 27:1643-1655

CHANGE C (2007) IPCC Fourth Assessment Report. The Physical Science Basis

Chen J, Brissette FP, Leconte R (2011) Uncertainty of downscaling method in quantifying the impact of climate change on hydrology. J Hydrol 401:190-202

Clarke L, Edmonds J, Jacoby H, Pitcher H, Reilly J, Richels R (2007) Scenarios of greenhouse gas emissions and atmospheric concentrations. US Department of Energy Publications, 6

Crane RG, Hewitson BC (1998) Doubled $\mathrm{CO}_{2}$ precipitation changes for the Susquehanna Basin: down-scaling from the Genesis general circulation model. Int J Climatol 18:65-76

Diaz-Nieto J, Wilby RL (2005) A comparison of statistical downscaling and climate change factor methods: impacts on low flows in the River Thames, United Kingdom. Clim Change 69:245268

Directive WF (2000) EU Water framework directive. Directive 2000/60/EC

Dufresne J-L, Foujols M-A, Denvil S, Caubel A, Marti O, Aumont O, Balkanski Y, Bekki S, Bellenger H, Benshila R (2013) Climate change projections using the IPSL-CM5 Earth System Model: from CMIP3 to CMIP5. Clim Dyn 40:2123-2165

Ellis CJ, Coppins BJ, Dawson TP, Seaward MR (2007) Response of British lichens to climate change scenarios: trends and uncertainties in the projected impact for contrasting biogeographic groups. Biol Conserv 140:217-235
Engler S, Werner JP (2015) Processes prior and during the early 18th century irish famines - weather extremes and migration. Climate 3:1035-1056

Fealy R, Sweeney J (2008) Statistical downscaling of temperature, radiation and potential evapotranspiration to produce a multiple GCM ensemble mean for a selection of sites in Ireland. Irish Geogr 41:1-27

Fowler H, Blenkinsop S, Tebaldi C (2007) Linking climate change modelling to impacts studies: recent advances in downscaling techniques for hydrological modelling. Int J Climatol 27:15471578

Gharbia SS, Johnston P, Gill L, Pilla F (2016) Using GIS based algorithms for GCMs' performance evaluation. In: 18th IEEE Mediterranean Electrotechnical Conference MELECON 2016, Cyprus

Giorgi F, Christensen J, Hulme M, Von Storch H, Whetton P, Jones R, MEARNS L, Fu C, Arritt R, Bates B (2001) Regional climate information-evaluation and projections. Climate Change 2001: The Scientific Basis. Contribution of Working Group to the Third Assessment Report of the Intergouvernmental Panel on Climate Change [Houghton, JT et al.(eds)]. Cambridge University Press, Cambridge, United Kongdom and New York, US

Hay LE, Clark M (2003) Use of statistically and dynamically downscaled atmospheric model output for hydrologic simulations in three mountainous basins in the western United States. J Hydrol 282:56-75

Hay LE, Wilby RL, Leavesley GH (2000) A comparison of delta change and downscaled GCM scenarios for three mounfainous basins in THE UNITED STATES1. Wiley Online Library

Hewitson B, Crane R (2006) Consensus between GCM climate change projections with empirical downscaling: precipitation downscaling over South Africa. Int J Climatol 26:1315-1337

Hulme M, Carter TR (1999) Representing uncertainty in climate change scenarios and impact studies. Representing uncertainty in climate change scenarios and impact studies (Proc. ECLAT-2 Helsinki Workshop, 14-16 April, 1999 (Eds. T. Carter, M. Hulme and D. Viner). P 128 Climatic Research Unit, Norwich, UK, 1999. 11-37

Joubert A, Hewitson B (1997) Simulating present and future climates of southern Africa using general circulation models. Progress Phys Geogr 21:51-78

Kattenberg A, Giorgi F, Grassl H, Meehl G, Mitchell J, Stouffer R, Tokioka T, Weaver A, Wigley T (1996) Climate modelsprojections of future climate. Climate Change 1995: the Science of Climate Change. Contribution of Working Group I to the Second Assessment Report of the Intergovernmental Panel on Climate Change, 285-357

Kulkarni P, Baron PA, Willeke K (2011) Aerosol measurement: principles, techniques, and applications, John Wiley \& Sons

Kurosawa A (2004) Multigas reduction strategy under climate stabilization target. Contributed Paper, 181

Lindner M, Maroschek M, Netherer S, Kremer A, Barbati A, GarciaGonzalo J, Seidl R, Delzon S, Corona P, Kolström M (2010) Climate change impacts, adaptive capacity, and vulnerability of European forest ecosystems. For Ecol Manag 259:698-709

Maurer E, Hidalgo H (2008) Utility of daily vs. monthly large-scale climate data: an intercomparison of two statistical downscaling methods. Hydrol Earth Syst Sci 12:551-563

McCarthy T, Frankiewicz P, Cullen P, Blaszkowski M, O'Connor W, Doherty D (2008) Long-term effects of hydropower installations and associated river regulation on River Shannon eel populations: mitigation and management. Hydrobiologia 609:109-124

Meinshausen M, Smith SJ, Calvin K, Daniel JS, Kainuma M, Lamarque J, Matsumoto K, Montzka S, Raper S, Riahi K (2011) The RCP greenhouse gas concentrations and their extensions from 1765 to 2300. Clim Change 109:213-241 
Mitchell T, Osborn T (2005) ClimGen: a flexible tool for generating monthly climate data sets and scenarios. Tyndall Centre for Climate Change Research Working Paper

Moss RH, Babiker M, Brinkman S, Calvo E, Carter T, Edmonds JA, Elgizouli I, Emori S, Lin E, Hibbard K (2008) Towards new scenarios for analysis of emissions, climate change, impacts, and response strategies

Moss RH, Edmonds JA, Hibbard KA, Manning MR, Rose SK, van Vuuren DP, Carter TR, Emori S, Kainuma M, Kram T (2010) The next generation of scenarios for climate change research and assessment. Nature 463:747-756

New M, Hulme M (2000) Representing uncertainty in climate change scenarios: a Monte-Carlo approach. Integr Assess 1:203-213

Pachauri R, Reisinger A (2007) IPCC fourth assessment report. IPCC, Geneva

Prudhomme C, Reynard N, Crooks S (2002) Downscaling of global climate models for flood frequency analysis: where are we now? Hydrol Processes 16:1137-1150

Quintana Segui P, Ribes A, Martin E, Habets F, Boé J (2010) Comparison of three downscaling methods in simulating the impact of climate change on the hydrology of Mediterranean basins. J Hydrol 383:111-124

Ramirez J, Jarvis A (2008) High resolution statistically downscaled future climate surfaces. International Center for Tropical Agriculture (CIAT)

Riahi K, Grübler A, Nakicenovic N (2007) Scenarios of long-term socio-economic and environmental development under climate stabilization. Technol Forecast Soc Change 74:887-935

Salathe EP, Mote PW, Wiley MW (2007) Review of scenario selection and downscaling methods for the assessment of climate change impacts on hydrology in the United States Pacific Northwest. Int J Climatol 27:1611-1621

Seguí PQ, Ribes A, Martin E, Habets F, Boé J (2010) Comparison of three downscaling methods in simulating the impact of climate change on the hydrology of Mediterranean basins. J Hydrol 383:111-124

Smith SJ, Wigley $\mathrm{T}$ (2006) Multi-gas forcing stabilization with MiniCAM. The Energy Journal, 373-391

Solomon S (2007) Climate change 2007-the physical science basis: working group I contribution to the fourth assessment report of the IPCC, Cambridge University Press

Stocker TF, Qin D, Plattner G-K, Tignor M, Allen SK, Boschung J, Nauels A, Xia Y, Bex V, Midgley PM (2013a) Climate change 2013: the physical science basis. Intergovernmental Panel on Climate Change, Working Group I Contribution to the IPCC Fifth Assessment Report (AR5)(Cambridge Univ Press, New York)

Stocker TF, Qin D, Plattner G, Tignor M, Allen S, Boschung J, Nauels A, Xia Y, Bex V, Midgley P (2013b) Climate change 2013: the physical science basis. Intergovernmental panel on climate change, working group I contribution to the IPCC fifth assessment report (AR5). New York: Cambridge University Press
Sweeney J, Brereton T, Byrne C, Charlton R, Emblow, C., FEALY, R., HOLDEN, N., JONES, M., DONNELLY, A. \& MOORE, S. 2003. Climate Change: Scenarios \& Impacts for Ireland (2000LS-5.2. 1-M1) ISBN: 1-84095-115-X

Taylor KE (2001) Summarizing multiple aspects of model performance in a single diagram. J Geophys Res Atmos 106:71837192

Taylor KE, Stouffer RJ, Meehl GA (2009a) A summary of the CMIP5 experiment design. WCRP, submitted

Taylor KE, Stouffer RJ, Meehl GA (2009b) A summary of the CMIP5 experiment design. PCDMI Rep, 33

Taylor KE, Stouffer RJ, Meehl GA (2012) An overview of CMIP5 and the experiment design. Bull Am Meteorol Soc 93:485-498

Tripathi S, Srinivas V, Nanjundiah RS (2006) Downscaling of precipitation for climate change scenarios: a support vector machine approach. J Hydrol 330:621-640

van Vuuren DP, den Elzen MG, Lucas PL, Eickhout B, Strengers BJ, van Ruijven B, Wonink S, van Houdt R (2007) Stabilizing greenhouse gas concentrations at low levels: an assessment of reduction strategies and costs. Clim Change 81:119-159

van Vuuren DP, Edmonds J, Kainuma M, Riahi K, Thomson A, Hibbard K, Hurtt GC, Kram T, Krey V, Lamarque J-F (2011) The representative concentration pathways: an overview. Clim Change 109:5-31

von Storch H, Zorita E, Cubasch U (1993) Downscaling of global climate change estimates to regional scales: an application to Iberian rainfall in wintertime. J Clim 6:1161-1171

Wang S, McGrath R, Semmler T, Sweeney C, Nolan P (2006) The impact of the climate change on discharge of Suir River Catchment (Ireland) under different climate scenarios. Nat Haz Earth Syst Sci 6:387-395

Whetton P, Mcinnes K, Jones R, Hennessy K, Suppiah R, Page C, Bathols J, Durack P (2006) Australian climate change projections for impact assessment and policy application: a review. CSIRO Marine and Atmospheric Research

Wilby RL, Harris I (2006) A framework for assessing uncertainties in climate change impacts: low-flow scenarios for the River Thames, UK. Water Resources Research, 42

Wilby RL, Wigley T (1997) Downscaling general circulation model output: a review of methods and limitations. Prog Phys Geogr 21:530-548

Willems P, Vrac M (2011) Statistical precipitation downscaling for small-scale hydrological impact investigations of climate change. J Hydrol 402:193-205

Xiaoge X, Li Z, Jie Z, Tongwen W, Yongjie F (2013) Climate change projections over East Asia with BCC_CSM1. 1 climate model under RCP scenarios. 気象集誌. 第 2 輯, 91, 413-429

Zorita E, von Storch H (1999) The analog method as a simple statistical downscaling technique: comparison with more complicated methods. J Clim 12:2474-2489 